\title{
The prevalence of postoperative pain in a cross- sectional group of patients after day-case surgery in a university hospital
}

Citation for published version (APA):

Gramke, H. F., de Rijke, J. M., van Kleef, M., Raps, F., Kessels, A. G., Peters, M. L., Sommer, M., \& Marcus, M. A. (2007). The prevalence of postoperative pain in a cross-sectional group of patients after day-case surgery in a university hospital. Clinical Journal of Pain, 23(6), 543-548.

https://doi.org/10.1097/AJP.0b013e318074c970

Document status and date:

Published: 01/01/2007

DOI:

10.1097/AJP.0b013e318074c970

Document Version:

Publisher's PDF, also known as Version of record

Document license:

Taverne

Please check the document version of this publication:

- A submitted manuscript is the version of the article upon submission and before peer-review. There can be important differences between the submitted version and the official published version of record.

People interested in the research are advised to contact the author for the final version of the publication, or visit the DOI to the publisher's website.

- The final author version and the galley proof are versions of the publication after peer review.

- The final published version features the final layout of the paper including the volume, issue and page numbers.

Link to publication

\footnotetext{
General rights rights.

- You may freely distribute the URL identifying the publication in the public portal. please follow below link for the End User Agreement:

www.umlib.nl/taverne-license

Take down policy

If you believe that this document breaches copyright please contact us at:

repository@maastrichtuniversity.nl

providing details and we will investigate your claim.
}

Copyright and moral rights for the publications made accessible in the public portal are retained by the authors and/or other copyright owners and it is a condition of accessing publications that users recognise and abide by the legal requirements associated with these

- Users may download and print one copy of any publication from the public portal for the purpose of private study or research.

- You may not further distribute the material or use it for any profit-making activity or commercial gain

If the publication is distributed under the terms of Article $25 \mathrm{fa}$ of the Dutch Copyright Act, indicated by the "Taverne" license above, 


\title{
The Prevalence of Postoperative Pain in a Cross-sectional Group of Patients After Day-case Surgery in a University Hospital
}

\author{
Hans-Fritz Gramke, MD,* Janneke M. de Rijke, PhD, $\dagger$ Maarten van Kleef, MD, PhD,* \\ Freya Raps, MD,* Alfons G. H. Kessels, MD, MSc,\$ Madelon L. Peters, PhD, $\S$ \\ Michael Sommer, MD,* and Marco A. E. Marcus, MD, PhD*
}

Objectives: Although a great variety of surgical procedures are performed on an ambulatory basis, little is known about postoperative pain experience at home after ambulatory surgery. This study was performed to assess the prevalence and course of postoperative pain in the early postoperative period after ambulatory surgery.

Methods: Over a period of 4 months, 648 patients who underwent day-case surgery were included in our study. Data were collected with interviews and questionnaires. Pain intensity was measured using a visual analog scale (VAS) during 4 days after surgery. Side effects of anesthesia and analgesia techniques were also recorded.

Results: On the day of the operation, $26 \%$ of the patients had moderate to severe pain (defined as mean VAS $>40 \mathrm{~mm}$ ). Mean VAS-scores were greater than $40 \mathrm{~mm}$ in $21 \%$ on postoperative day (POD) 1 , in $13 \%$ on POD 2 , in $10 \%$ on POD 3 , and in $9 \%$ on POD 4. Operations of nose and pharynx, abdominal operations, plastic surgery of the breasts, and orthopedic operations were the most painful procedures during the first 48 hours.

Discussion: This study showed that an important number of patients still experience moderate to severe pain in the postoperative period after day-case surgery even after a 4-day period. Furthermore, the type of operation should be considered when planning postoperative analgesia for ambulatory surgery.

Key Words: postoperative pain, ambulatory surgery, analgesia, acute pain

(Clin J Pain 2007;23:543-548)

Received for publication May 2, 2006; revised December 21, 2006; accepted April 17, 2007.

From the *Department of Anesthesiology and Pain Therapy; †Pain Management and Research Centre; \$Department of Clinical Epidemiology and Medical Technology Assessment, University Hospital Maastricht; and §Department of Medical, Clinical and Experimental Psychology, Maastricht University, Maastricht, The Netherlands.

Reprints: Hans-Fritz Gramke, MD, Department of Anesthesiology and Pain Therapy, University Hospital Maastricht, PO Box 5800, 6202 AZ Maastricht, The Netherlands (e-mail: hgra@sane.azm.nl). Copyright (C) 2007 by Lippincott Williams \& Wilkins
Dostoperative pain therapy after ambulatory surgery is a challenge. It requires effective analgesic techniques with minimal side effects, which can be easily managed at home and which are intrinsically safe for the patient. The method of choice to treat postoperative pain in the ambulatory setting is a multimodal analgesic approach combining intraoperative opioids, acetaminophen, nonsteroidal anti-inflammatory drugs, weak opioids, and local and regional anesthesia. ${ }^{1}$

At present, a great variety of surgical procedures are performed in an ambulatory setting. With progressing expansion of ambulatory surgery, the postoperative pain therapy for these procedures is getting more attention. Some data about pain experience at home after ambulatory surgery already exist. These previous reports showed a high incidence of postoperative pain after day surgery. ${ }^{2-6}$ Severe pain not only causes discomfort and suffering, but also prevents the patient from resuming his or her daily activities, which can be of major socioeconomic relevance. Besides, insufficient postoperative pain therapy may have a negative impact on perioperative morbidity and mortality and decrease the postoperative quality of life. ${ }^{7-10}$

Most of the published reports on pain after ambulatory surgery lack a reasonable time of follow-up or studied only a small group of patients. However, understanding the course of postoperative pain would be of utmost importance for future quality improvement of postoperative pain therapy. This study was designed to investigate the prevalence and course of postoperative pain in the early postoperative period after ambulatory surgery using an approach of balanced analgesia for postoperative pain therapy.

\section{MATERIALS AND METHODS}

\section{Study Design}

A cross-sectional study was carried out. Data were collected with interviews and questionnaires.

\section{Study Population}

After approval of the institutional ethics committee and written informed consent, we enrolled patients undergoing ambulatory surgery at the University Hospital 
Maastricht in the Netherlands from October 15, 2002 to January 31, 2003. Excluded were patients younger than 18 years, patients with limitations of self-expression, visual dysfunction or Dutch language problems, and patients with acute surgery and patients receiving local anesthesia.

\section{Study Procedure and Measures}

After arrival on the ambulatory surgery unit, the patients were approached by a trained research assistant who explained the purpose and methods of the study. A $100-\mathrm{mm}$ visual analog scale (VAS), anchored "no pain" and "worst pain I can imagine," was used for measuring pain intensity preoperatively and all following evaluations of pain intensity. Furthermore, socio-demographic variables were recorded such as date of birth, sex, and education.

Approximately 1 hour preoperatively acetaminophen $1000 \mathrm{mg}$ or naproxen $500 \mathrm{mg}$ were administered per os (postoperative) if not contraindicated. The type of anesthesia was not regulated by the study protocol. The choice of technique and agents to be used were left to the individual anesthesiologist and patient. In consultation with the surgeons, wounds were infiltrated with bupivacaine when appropriate. Patients who received localregional anesthesia techniques were not additionally treated with wound infiltration. After surgery, the patients stayed in the Post anesthesia Care Unit for early recovery. In the Post anesthesia Care Unit, patients were given piritramide intravenously ( 1 to $5 \mathrm{mg}$ ) if necessary until their pain scored a VAS below $40 \mathrm{~mm}$. When they were sufficiently recovered and did not show clinically relevant side effects or pain the patients were transferred to the holding area of the ambulatory surgery ward for complete recovery. Further postoperative pain therapy consisted of the combination of acetaminophen and naproxen. Before discharge, the patients were provided with a box of 20 tablets of acetaminophen $500 \mathrm{mg}$ and 10 tablets of naproxen $500 \mathrm{mg}$ together with written instructions concerning use and dosage (acetaminophen $1000 \mathrm{mg}$ postoperative 4 times daily; naproxen $500 \mathrm{mg}$ postoperative twice daily). If this regimen was not expected to be sufficient, patients were additionally provided with a prescription for tramadol $50 \mathrm{mg}$ postoperative up to a maximum of 3 times daily. The decision to provide acetaminophen or naproxen or both or to add a prescription for tramadol was left to the anesthesiologist.

Pain, nausea, and other symptoms were measured 1 hour and 2 hours after the operation and at discharge. Type of anesthesia and administered analgesic medication were documented. At discharge, patients received a pain diary which had to be filled out from the evening of the day of surgery [postoperative day (POD) 0] to day 4 after the operation (POD 4) at 9.00 AM, 3.00 PM, and 9.00 PM. Patient satisfaction was evaluated using a 10-point scale in the style of the Dutch school grades system. Patients were contacted by phone on the third POD to encourage them to return the diary in a special prepaid envelope. When a diary was not returned within 14 days after surgery, the corresponding patient was contacted by phone.

\section{Statistical Analyses}

The population was divided into subgroups of similar operations to get results, which can be interpreted in the clinical context. A mean VAS-score of higher than $40 \mathrm{~mm}$ was considered to be at least moderate pain and accordingly insufficient analgesia. Mean VAS-scores on days 0 to 4 were calculated using the average of the 3 scores recorded each day for each individual. $\chi^{2}$ tests were used to determine differences between groups. A $P$ value less than 0.05 was considered as statistically significant.

\section{RESULTS}

Six hundred and sixty (89\%) of 744 eligible patients consented to participate. Twelve patients were excluded afterwards because of logistic problems, leaving 648 for analysis.

However, seventy-seven patients $(12 \%)$ did not return the pain diary and some patients did not answer all the questions in the diary. Therefore, results are presented as percentages and absolute numbers, and a total of 648 are seldom reached. Patient characteristics are shown in Table 1. More female patients participated

\begin{tabular}{|c|c|c|}
\hline & n & $\%$ \\
\hline \multicolumn{3}{|l|}{ Age (y) } \\
\hline$\leq 34$ & 131 & 20 \\
\hline $35-49$ & 189 & 29 \\
\hline $50-64$ & 201 & 31 \\
\hline $65-79$ & 107 & 17 \\
\hline$\geq 80$ & 20 & 3 \\
\hline \multicolumn{3}{|l|}{ Sex } \\
\hline Male & 281 & 43 \\
\hline Female & 367 & 57 \\
\hline \multicolumn{3}{|l|}{ Educational background } \\
\hline Elementary school & 221 & 34 \\
\hline Intermediate & 247 & 38 \\
\hline Higher degree, university & 170 & 26 \\
\hline Unknown & 10 & 2 \\
\hline \multicolumn{3}{|l|}{ Analgesic use at home } \\
\hline Acetaminophen & 39 & 6 \\
\hline NSAIDs & 43 & 7 \\
\hline Weak opioids & 12 & 2 \\
\hline None & 554 & 85 \\
\hline \multicolumn{3}{|l|}{ Type of anesthesia } \\
\hline General & 400 & 62 \\
\hline Loco-regional & 248 & 38 \\
\hline \multicolumn{3}{|l|}{ Type of surgery } \\
\hline General surgery & 195 & 30 \\
\hline Orthopedics & 165 & 26 \\
\hline Ophthalmology & 93 & 14 \\
\hline Plastic surgery & 72 & 11 \\
\hline Gynecology & 59 & 9 \\
\hline ENT surgery & 36 & 6 \\
\hline Urology & 19 & 3 \\
\hline Oral surgery & 9 & 1 \\
\hline
\end{tabular}

NSAIDs indicate nonsteroidal anti-inflammatory drugs. 
in this study compared with men (57\% vs. $43 \%)$. Twenty patients were above 80 years (3\%). A majority of patients underwent general surgical or orthopedic operations (32\% and $25 \%$, respectively). Only a few urologic patients were included $(3 \%)$. General anesthesia was applied to $62 \%$ of the patients (400 patients), whereas $38 \%$ of the patients (248 patients) received localregional technique. Local-regional techniques included spinal anesthesia (150 patients), peripheral nerve blocks (10 patients), retrobulbar and sub-Tenon anesthesia (72 patients), and intravenous regional anesthesia (16 patients).

Fifty-nine patients $(9 \%)$ were treated in terms of short stay admission $(<24 \mathrm{~h})$. Fifteen patients $(2 \%)$ were readmitted to the hospital or visited their general practitioner during the postoperative course on an unplanned basis.

Before the operation, 37 patients $(6 \%)$ had VASscores of more than $40 \mathrm{~mm}$. The course of pain in the postoperative period is shown in Figure 1. On the day of the operation (POD 0), mean VAS-scores were greater than $40 \mathrm{~mm}$ in $26 \%$ of the patients (164 patients). Mean VAS-scores were greater than $40 \mathrm{~mm}$ in $21 \%$ (119 patients) on POD 1, in 13\% (78 patients) on POD 2, in $10 \%$ (58 patients) on POD 3, and in 9\% (50 patients) on POD 4. On POD 0, significantly less patients had a mean VAS-score above $40 \mathrm{~mm}$ when receiving a local-regional anesthesia technique $(16 \%$ vs. $31 \% ; P<0.001$ ) (not shown).
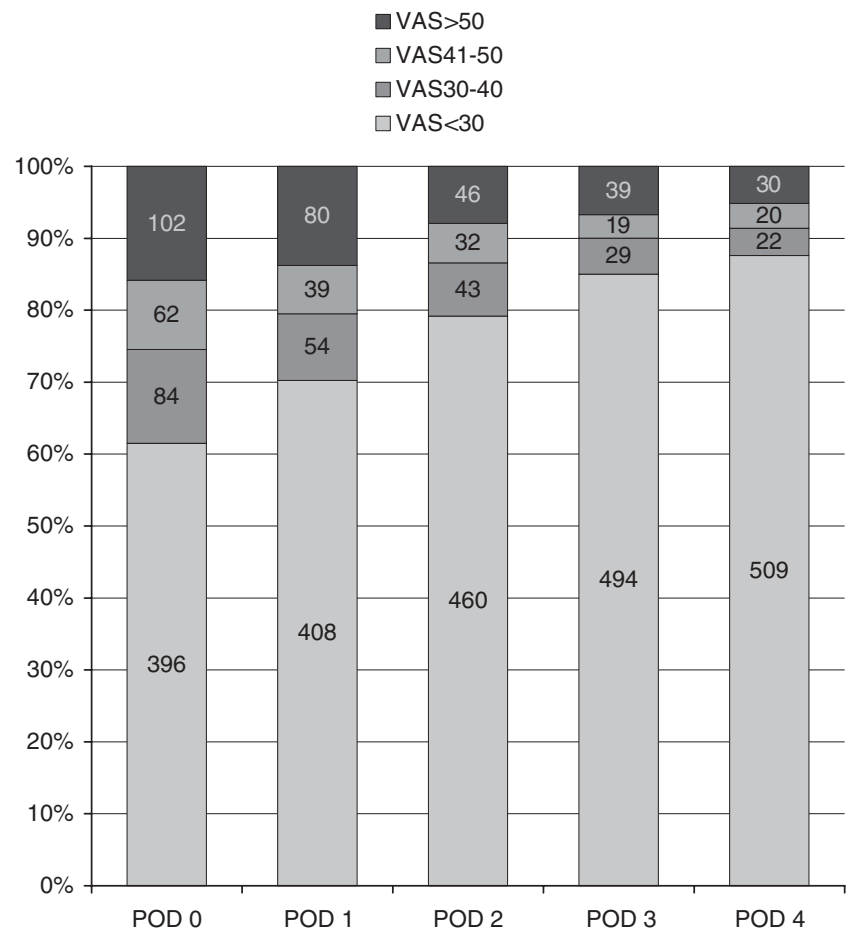

FIGURE 1. All patients: the course of pain in the postoperative period. Labels represent number of patients. VAS in millimeters.
Figure 2 shows the distribution of those patients showing a mean VAS-score of higher than $40 \mathrm{~mm}$ during POD 0 and POD 1 for the different subgroups of clinical comparable operations. In the subgroups nasopharynx $(\mathrm{n}=16)$, general surgery-abdomen $(\mathrm{n}=45)$, plastic surgery-mamma $(\mathrm{n}=23)$, orthopedics-lower extremity $(\mathrm{n}=18)$, and orthopedics-upper extremity $(\mathrm{n}=27)$ more than $25 \%$ of patients had a mean VAS-score of higher than $40 \mathrm{~mm}$ on both days. None of the patients who underwent cataract surgery $(\mathrm{n}=78)$ had a mean VASscore of higher than $40 \mathrm{~mm}$ on POD 1.

\section{Use of Analgesics}

Ninety-six percent (622 patients) actually received acetaminophen $1000 \mathrm{mg}$ or naproxen $500 \mathrm{mg}$ approximately 1 hour before the operation started. The postoperative use of analgesics is shown in Table 2 . Twenty-two percent of the patients $(n=140)$ were treated with piritramide intravenously during the early postoperative period on POD 0 . There were significantly fewer patients who received piritramide in the group treated with a local-regional technique compared with the group treated with general anesthesia $(P<0.001)$ (not shown). No strong opioids were used after discharge. The intake of analgesic medication decreased with time. On POD 4, $13 \%$ of the patients $(n=86)$ were still using acetaminophen, $9 \%$ of the patients $(n=58)$ used naproxen, $3 \%$ of the patients $(\mathrm{n}=18)$ used the combination of both, and $1 \%$ (5 patients) took tramadol.

\section{Patient Satisfaction}

Patient satisfaction regarding postoperative analgesia was rated by 542 of the 648 included patients. Ninetyfour percent (507 patients) were satisfied with the analgesic treatment they received. Seven or higher on a 10 -point scale in the style of the Dutch school grades was considered satisfied with analgesic treatment. There was no difference between patients who underwent general anesthesia and patients who were treated with localregional techniques. Ninety-one percent of the patients $(\mathrm{n}=549)$ would choose the same analgesic treatment again if necessary.

\section{Side Effects}

The incidence of side effects of anesthesia is shown in Table 3. During the entire study period, patients who received general anesthesia had a significantly higher incidence of nausea compared with patients who were treated with local-regional techniques. The incidence of postoperative drowsiness was also significantly higher in the patients who had general anesthesia during the entire study period. Patients who were treated with localregional techniques had significantly more pruritus on the day of the operation but not during the rest of the study period. We observed no difference concerning the incidence of headache and backache between localregional and general anesthesia groups. 
FIGURE 2. Type of surgery and pain intensity. Percentage of patients with mean VAS $>40 \mathrm{~mm}$ for different types of surgery during the day of the operation (POD 0) and the POD 1.
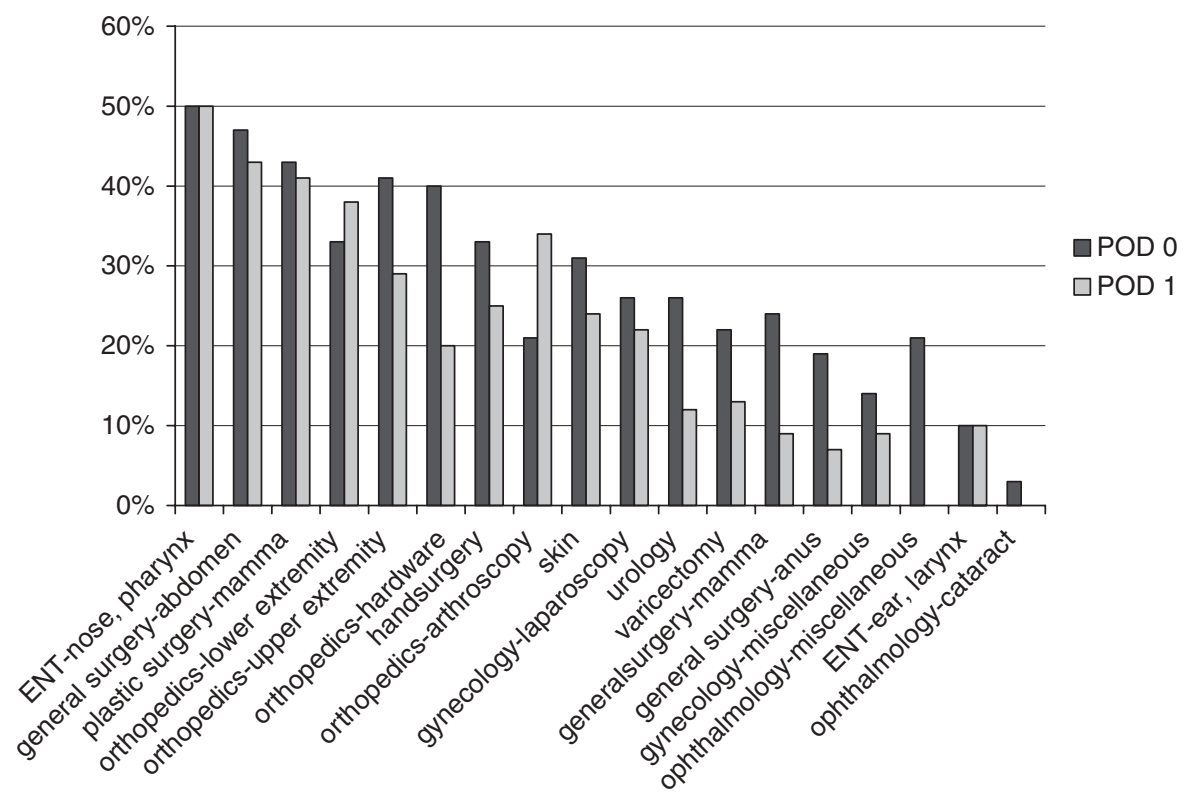

\section{DISCUSSION}

In this study, with a multimodal approach of postoperative analgesia using acetaminophen, nonsteroidal anti-inflammatory drugs, opioids, and local anesthetics, a significant number of patients reported moderate to severe pain in the postoperative period after day-case surgery even after a 4-day period. Operations of nose and pharynx, abdominal operations, plastic surgery of the breasts, and orthopedic operations of the extremities were the most painful procedures during the first 48 hours.

Insufficient postoperative analgesia can be one of the major pitfalls after ambulatory surgery. Reviewing the literature over the past 10 years, similar results were shown in previous reports. ${ }^{3,4,11,12}$ Despite more sophisticated postoperative analgesia techniques using combinations of medications with different mechanisms of action in the context of multimodal analgesia, the prevalence of postoperative pain after day surgery seems to be unaffected. One reason for this could be that the spectrum

TABLE 2. All Patients $(n=648)$. Use of Analgesic Medication in the Postoperative Period

\begin{tabular}{lcccc}
\hline & $\begin{array}{c}\text { POD 1 } \\
\mathbf{\%}\end{array}$ & $\begin{array}{c}\text { POD 2 } \\
\mathbf{\%}\end{array}$ & $\begin{array}{c}\text { POD 3 } \\
\mathbf{\%}\end{array}$ & $\begin{array}{c}\text { POD 4 } \\
\mathbf{\%}\end{array}$ \\
\hline None & 23 & 38 & 52 & 59 \\
Acetaminophen & 31 & 21 & 13 & 13 \\
NSAID & 19 & 16 & 10 & 9 \\
$\begin{array}{l}\text { Acetaminophen + NSAID } \\
\text { Acetaminophen/NSAID }\end{array}$ & 10 & 6 & 5 & 3 \\
$\quad$ tramadol & 1 & 1 & 1 & 1 \\
Missing data & 16 & 19 & 19 & 15 \\
\hline
\end{tabular}

NSAID indicates nonsteroidal anti-inflammatory drug. of surgery performed in an ambulatory setting extended to more complex operations during the past decade, for example, mastectomy ${ }^{13}$ and laparoscopic cholecystectomy. ${ }^{14}$ Another factor lies in the nature of the ambulatory setting: patient compliance concerning the use of analgesics during the postoperative period at home is very difficult to control. In this study, we found a low postoperative use of analgesics. On the second day after the operation, almost half of the patients did not use any analgesics despite provision of written instructions and a box of tablets. This is conform to findings of other reports. ${ }^{4,15,16}$ Whether the reason for this low use of postoperative analgesics is fear of side effects of analgesics or other factors play a role as well is not clear. In a study by Watt-Watson and coworkers, ${ }^{15}$ it was stated that patients quite their analgesic medication because of previous or current experiences with constipation and nausea due to pain medication. Half of the patients stopped taking analgesics at 72 hours despite moderate pain in their study. However, constipation and nausea are side effects of opioid analgesics, which were used at home by only very few patients in our study. So, we cannot conclude that the reasons for not taking analgesics were the same in our study. In the investigation of Beauregard and colleagues, ${ }^{4}$ more than half of the patients did not take any analgesics at 48 hours, whereas the study by Apfelbaum and colleagues ${ }^{2}$ revealed that $94 \%$ of patients thought that some analgesics, opioid and nonopioid, prescribed after surgery caused adverse effects. So, fear for side effects of analgesic medication seems to be a relevant factor affecting patient compliance for postoperative analgesics. Thus good patient education seems to be a key factor for optimal pain management after day surgery. Otherwise patient expectations of a certain level of postoperative pain and the fear for side effects and 
TABLE 3. Side Effects of Anesthesia/Analgesia: General Versus Local-regional Anesthesia Techniques

\begin{tabular}{|c|c|c|c|c|c|c|c|c|c|c|}
\hline & \multicolumn{2}{|c|}{ POD 0} & \multicolumn{2}{|c|}{ POD 1} & \multicolumn{2}{|c|}{ POD 2} & \multicolumn{2}{|c|}{ POD 3} & \multicolumn{2}{|c|}{ POD 4} \\
\hline & $\begin{array}{c}\text { General } \\
\%\end{array}$ & $\begin{array}{c}\text { Local-regional } \\
\%\end{array}$ & $\begin{array}{c}\text { General } \\
\%\end{array}$ & $\begin{array}{c}\text { Local-regional } \\
\%\end{array}$ & $\begin{array}{c}\text { General } \\
\%\end{array}$ & $\begin{array}{c}\text { Local-regional } \\
\%\end{array}$ & $\begin{array}{c}\text { General } \\
\%\end{array}$ & $\begin{array}{c}\text { Local-regional } \\
\%\end{array}$ & $\begin{array}{c}\text { General } \\
\%\end{array}$ & $\begin{array}{c}\text { Local-regiona } \\
\%\end{array}$ \\
\hline Nausea & 42 & $17 *$ & 22 & $11^{*}$ & 15 & 9* & 12 & $4 *$ & 9 & $3 *$ \\
\hline Headache & 16 & 13 & 13 & 9 & 10 & 10 & 11 & 10 & 7 & 5 \\
\hline Backache & 12 & 12 & 11 & 14 & 9 & 9 & 8 & 5 & 6 & 5 \\
\hline Drowsiness & 34 & $10^{*}$ & 19 & $5^{*}$ & 13 & $4 *$ & 8 & $2 *$ & 7 & $2 *$ \\
\hline
\end{tabular}

POD 0 to 4

$* P<0.05$.

addiction to analgesics can impede their willingness to use prescribed analgesics according to the postoperative treatment regimen. On the other hand, one must not conclude that a low use of postoperative analgesics in the face of high pain scores means adequate pain control.

Some authors advise providing ambulatory surgery patients with an aggressive analgesic treatment during their hospital stay, to minimize the pain they will experience at home. Furthermore, a multimodal approach has been recommended with analgesic drugs regularly given and adjusted to individual needs, rather than waiting for the patient to ask for pain medication. ${ }^{4,12,17}$ For a good anticipation of analgesic needs of a patient, it is very helpful to know which operations in general cause a lot of postoperative pain and which operations are rather painless. ${ }^{18}$ In accordance with the publications of Jensen and coworkers, ${ }^{19}$ and Beauregard and colleagues, ${ }^{4}$ we think a level of moderate pain corresponds to a VAS higher than $40 \mathrm{~mm}$. A higher level of postoperative pain is not desirable and should be prevented. Starting from this assumption, we evaluated the proportions of patients with mean VAS score higher than $40 \mathrm{~mm}$ for subgroups of similar operations. Operations of nose and pharynx, abdominal operations (eg, inguinal herniography), plastic operations of the breast (eg, breast augmentation), and orthopedic surgery of the lower and upper extremity (eg, surgery of the shoulder) had a high proportion $(>25 \%$ on POD 0 and POD 1) of patients with a mean VAS score higher than $40 \mathrm{~mm}$ and a level of moderate or even severe pain, respectively. These findings are consistent with the results of Chung and coworkers. ${ }^{16}$ A point of criticism might be that the subgroups still consist of a variety of operations and that the anesthesia technique was not standardized. But taking this into account, when interpreting our results, a clue for anticipation of postoperative pain is provided.

Despite a high incidence of postoperative pain, most patients stated that they were satisfied with their treatment $(94 \%)$. This paradoxical finding is reported in most studies concerning postoperative pain. . $, 3,11,20,21^{2}$ Because of this lack of correlation with postoperative pain and the complex nature of this parameter, patient satisfaction is probably not a meaningful parameter to examine the quality of postoperative analgesia.

In conclusion, this study confirms that despite all scientific progress and new therapeutic approaches, many patients do not receive sufficient postoperative analgesia after ambulatory surgery. That is, many patients still report moderate to severe postoperative pain, defined by a VAS score of higher than $40 \mathrm{~mm}$. Due to the low compliance with therapeutic regimen, patient education may be a first starting point for improvement. Furthermore, the type of operation should be considered when planning postoperative analgesia for ambulatory surgery.

\section{REFERENCES}

1. Chauvin M. State of the art of pain treatment following ambulatory surgery. Eur J Anaesth. 2003;20(suppl 28):3-6.

2. Apfelbaum JL, Chen C, Mehta SS, et al. Postoperative pain experience: results from a national survey suggest postoperative pain continues to be undermanaged. Anesth Analg. 2003;97: 534-540.

3. Rawal N, Hylander J, Nydahl PA, et al. Survey of postoperative analgesia following ambulatory surgery. Acta Anaesthesiol Scand. 1997;41:1017-1022.

4. Beauregard L, Pomp A, Choinière M. Severity and impact of pain after day-surgery. Can J Anaesth. 1998;45:304-311.

5. Chung F, Un V, Su J. Postoperative symptoms 24 hours after ambulatory anaesthesia. Can J Anaesth. 1996;43:1121-1127.

6. Mc Grath B, Elgendy H, Chung F, et al. Thirty percent of patients have moderate to severe pain 24 hours after ambulatory surgery: a survey of 5,703 patients. Can J Anaesth. 2004;51:886-891.

7. Warner MA, Shields SE, Chute CG. Major morbidity and mortality within 1 month of ambulatory surgery and anesthesia. JAMA. 1993;270:1437-1441

8. Shipton EA, Tait B. Flagging the pain: preventing the burden of chronic pain by identifying and treating risk factors in acute pain. Eur J Anaesthesiol. 2005;22:405-412.

9. Perkins FM, Kehlet H. Chronic pain as an outcome of surgery. A review of predictive factors. Anesthesiology. 2000;93: $1123-1133$

10. Horvath KJ. Postoperative recovery at home after ambulatory gynecologic laparoscopic surgery. J Perianesth Nurs. 2003;18: 324-334.

11. McHugh GA, Thoms GMM. The management of pain following day-case surgery. Anaesthesia. 2002;57:270-275.

12. Pavlin DJ, Chen C, Penaloza DA, et al. A survey of pain and other symptoms that affect the recovery process after discharge from an ambulatory surgery unit. $J$ Clin Anesth. 2004;16: 200-206.

13. Dooley WC. Ambulatory mastectomy. Am J Surg. 2002;184:545-548. 
14. Jain PK, Hayden JD, Sedman PC, et al. A prospective study of ambulatory laparoscopic cholecystectomy: training economic, and patient benefits. Surg Endosc. 2005;19:1082-1085.

15. Watt-Watson J, Chung F, Chan VWS, et al. Pain management following discharge after ambulatory same-day surgery. $J$ Nurs Manag. 2004;12:153-161.

16. Chung F, Ritchie E, Su J. Postoperative pain in ambulatory surgery. Anesth Analg. 1997;85:808-816.

17. Joshi GP. Pain management after ambulatory surgery. Ambul Surg. 1999;7:3-12.
18. Coll AM, Ameen JR, Moseley LG. Reported pain after day surgery: a critical literature review. $J$ Adv Nurs. 2004;46:53-65.

19. Jensen MP, Chen C, Brugger AM. Interpretation of Visual Analog Scale ratings and change scores: a reanalysis of two clinical trials of postoperative pain. J Pain. 2003;4:407-414.

20. Jensen MP, Chen C, Brugger AM. Postsurgical pain outcome assessment. Pain. 2002;99:101-109.

21. Ward SE, Gordon DB. Patient satisfaction and pain severity as outcomes in pain management: a longitudinal view of one setting's experience. J Pain Symptom Manage. 1996;11: 242-251. 